\title{
Clinical and genetic profile of congenital long QT syndrome in Hong Kong: a 20-year experience in paediatrics
}

\author{
SY Kwok, Anthony PY Liu, Cindy YY Chan, KS Lun, Jasmine LF Fung, Christopher CY Mak, \\ Brian HY Chung *, TC Yung
}

\section{A B S T R A C T}

Introduction: Congenital long QT syndrome (LQTS) is a genetically transmitted cardiac channelopathy that can lead to sudden cardiac death. This study aimed to report the clinical and genetic characteristics of all young patients diagnosed with LQTS in the only tertiary paediatric cardiology centre in Hong Kong.

Methods: This is a retrospective review of all paediatric and young adult patients diagnosed at our centre with LQTS from January 1997 to December 2016. The diagnosis of LQTS was established with a corrected QT interval (QTc) $\geq 480 \mathrm{~ms}$, Schwartz score of $>3$ points, or the presence of a pathogenic mutation.

Results: Fifty-nine patients (33 males) from 52 families were included, with a mean age of 8.17 years (range, 0.00-16.95 years) at presentation. Five patients had concomitant congenital heart diseases. The mean follow-up duration was $5.33 \pm 4.65$ years. The mean QTc in the cohort was $504 \pm 47 \mathrm{~ms}$. They presented with syncope and convulsion (49\%), cardiac arrest (10\%), bradycardia and neonatal atrioventricular block (12\%). Fifteen (25\%) patients were asymptomatic at diagnosis. Thirty-eight (64.4\%) patients were confirmed to have a pathogenic mutation for LQTS genes. Forty-five (76.3\%) patients received beta blocker therapy. Thirteen
(22.0\%) patients required implantable cardioverter defibrillator. There was no mortality in the study period. The 1-, 5-, and 10-year breakthrough cardiac event-free rates were $93.0 \%, 80.7 \%$, and $72.6 \%$, respectively.

Conclusion: Identification of the disorder, administration of beta blockers, and lifestyle modification can prevent subsequent cardiac events in LQTS. Genotyping in patients with LQTS is essential in guiding medical therapy and improving prognosis.

\section{Hong Kong Med J 2018;24:561-70}

DOI: $10.12809 / \mathrm{hkmj} 187487$

\author{
SY Kwok, MB, ChB, FHKAM (Paediatrics) \\ ${ }^{2}$ APY Liu, MB, BS, FHKAM (Paediatrics) \\ ${ }^{1}$ CYY Chan, BSc \\ ${ }^{1}$ KS Lun, MB, BS, FHKAM (Paediatrics) \\ 2 JLF Fung, BBiomedSc \\ ${ }^{2}$ CCY Mak, MB, ChB \\ ${ }^{2}$ BHY Chung *, MB, BS, FHKAM (Paediatrics) \\ ${ }^{1}$ TC Yung, MB, BS, FHKAM (Paediatrics)
}

1 Department of Paediatric Cardiology, Queen Mary Hospital, Pokfulam, Hong Kong

Department of Paediatrics and Adolescent Medicine, Li Ka Shing Faculty of Medicine, The University of Hong Kong, Pokfulam, Hong Kong

* Corresponding author: bhychung@hku.hk

New knowledge added by this study

- Two-thirds of young long QT syndrome patients in Hong Kong carry pathogenic mutations. Concomitant congenital heart disease is present in $8.5 \%$ of these patients.

- The current treatment strategy for young long QT syndrome patients in Hong Kong includes lifestyle modification, beta blocker therapy, implantation of a cardioverter defibrillator, and sympathectomy.

- Young long QT syndrome patients in the present study have good prognosis. No mortality was reported in the medium-term follow-up.

Implications for clinical practice or policy

- Genetic testing should be performed for all patients with clinical diagnosis of long QT syndrome, to facilitate timely genotype-guided therapy and early detection of affected family members.

- The diagnosis of long QT syndrome should be considered in young patients presenting with syncope and convulsions, as well as those with bradycardia and atrioventricular block in early infancy.

- Sudden cardiac death associated with long QT syndrome is preventable. Facilities for genetic testing and inherited arrhythmia assessment are recommended.

\section{Introduction}

Congenital long QT syndrome (LQTS) is a lifethreatening cardiac arrhythmia syndrome, which leads to sudden death in young people. ${ }^{1}$ Congenital LQTS is characterised by prolonged QT interval (QTc) on electrocardiogram (ECG) and occurrence 


\section{香港先天性長QT綜合症的臨床和遺傳特徵： 20年兒科經驗 \\ 郭焱義、廖栢賢、陳鈺怡、倫建成、馮莉芳、麥駿宇、 鍾㑆言、翁德璋}

引言：先天性長QT綜合症（LQTS）是遺傳性心臟病，可導致心臟性 猝死。本研究旨在報告於香港唯一的三級兒科心臟科中心確診LQTS 所有年輕患者的臨床和遺傳特徵。

方法：這項回顧性研究分析 1997年1月至2016年12月期間在本中心確 診LQTS的所有兒科和年輕患者, 並基於經調正QT間期達 $480 \mathrm{~ms}$ 或以 上、Schwartz評分3分以上, 或存在致病突變診斷LQTS。

結果：納入52個家庭共59名患者（33名為男性），確診或病發時平均 年齡為 8.17 歲（年齡介乎 0.00 至 16.95 歲）。5名患者伴有先天性心藏 病。平均隨訪時間為 $5.33 \pm 4.65$ 年, 平均QTc間期為 $504 \pm 47 \mathrm{~ms}$ 。患

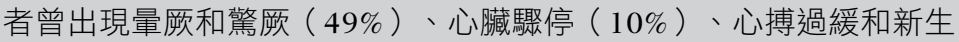
兒房室傳導阻滯（12\%）。15名（25\%）患者在診斷時並無症狀。確 認38名 (64.4\%) 患者具有LQTS基因的致病突變。45名（76.3\%）患 者接受 $\beta$ 受體阻滯劑治療。13名 $(22.0 \%)$ 患者需要植入式心律轉復除 顫器。研究期間沒有死亡病例。 1 年、 5 年及 10 年無隨後的心臟事件發 生率分別為 $93.0 \% 、 80.7 \%$ 和 $72.6 \%$ 。

結論：鑑定疾病、使用 $\beta$ 受體阻滯劑和改變生活方式可預防LQTS隨後 的心臟事件。LQTS患者的基因分型對於指導藥物治療和改善預後至 關重要。 mutation, irrespective of the QTc, was also used for diagnosis of LQTS. Secondary causes of LQTS were excluded.

Demographic data, clinical presentation, family history, QTc at presentation, and genetic tests were retrospectively reviewed. Clinically important presentation was defined as clinical symptoms or rhythm disturbances that warranted concern. Incidental findings of isolated prolonged QTc were not regarded as clinically important presentation.

We reviewed the treatment modalities, including beta blocker therapy, implantable cardioverter defibrillator (ICD), permanent pacemaker, and left cardiac sympathetic denervation. Clinical outcomes up to December 2016 were summarised. Syncope, seizure, aborted cardiac arrest, appropriate ICD shock, or sudden cardiac death after diagnosis of LQTS were considered as breakthrough cardiac events.

\section{Genetic test}

Genetic tests were offered to all patients after informed consent was provided by their parents or guardians. Blood samples were sent to the Molecular Genetics Laboratory of Victorian Clinical Genetic Services, Melbourne, Australia, for genetic testing. Before 2014, six common LQTS genes were tested (KCNQ1, KCNH2, SCN5A, KCNE1, KCNE2, $K C N J 2)$ by sequencing of the entire coding region of all known transcripts of the genes. Multiplex ligation-dependent probe amplification analysis was performed on five genes (KCNQ1, KCNH2, SCN5A, $K C N E 1, K C N E 2)$ to detect deletions or duplications. After 2014, next-generation sequencing was used to identify mutations in an arrhythmia gene panel to replace sequencing of the six LQTS genes (details of the arrhythmia full panel can be found at http:// www.vcgs.org.au/tests/cardiac-gene-panels). Before referral to our unit, 13 patients had genetic tests performed by local or overseas genetic testing centres.

Mutations in the LQTS loci classified as pathogenic or likely pathogenic were considered as genotype positive in our cohort. Cascade testing was offered to first-degree relatives of patients identified as genotype positive.

\section{Statistical analysis}

Statistical analysis was performed with the SPSS (Window version 17.0; SPSS Inc, Chicago [IL], United States). Continuous variables were expressed as mean \pm standard deviation, median and range. We used the standard $t$ test for comparisons of continuous data. The $\mathrm{P}<0.05$ were deemed statistically significant. Kaplan-Meier survival curves were created with censoring at first breakthrough cardiac event or last follow-up, and analysis was made using the log rank test. 


\section{Results}

\section{Demographics and clinical characteristics}

During the study period, 59 patients (33 males) in 52 families were identified who fulfilled the diagnostic criteria as described. Nine individuals were diagnosed by ECG screening of our index cases including a 25-year-old young adult. The mean follow-up duration of the cohort was $5.33 \pm 4.65$ years. Four patients were lost to follow-up, but no death was reported in the territory-wide Hospital Authority electronic patient record. Five patients were under the care of adult cardiologists at the follow-up.

Table 1 shows the characteristics of our patients. The mean age at diagnosis was $8.12 \pm 5.19$ years (range, 0-25 years). For those patients who had clinically important presentation, the mean age at presentation was $8.75 \pm 5.12$ years (range, $0.00-16.95$ years). Boys were younger than girls at presentation $(6.39 \pm 5.00$ years vs $10.51 \pm 4.55$ years, $\mathrm{P}=0.016)$.

The mean QTc of the cohort was $504 \pm 47 \mathrm{~ms}$. The median Schwartz score was 4 points (range, 1-6 points). Index patients had longer mean QTc $(512 \pm 46 \mathrm{~ms})$ when compared with screened family members $(462 \pm 25 \mathrm{~ms}, \mathrm{P}=0.002)$.

Five $(8.47 \%)$ patients had congenital heart defects: secundum atrial septal defect $(n=1$; genotype negative), ventricular septal defect $(n=1$; LQTS type 2 [LQT2]), tetralogy of Fallot $(n=2 ;$ LQT2 and LQTS type 8 [LQT8]), and transposition of great arteries $(\mathrm{n}=1$; genotype negative). One patient had bilateral sensorineural hearing loss and was subsequently confirmed to have LQTS type 1 (LQT1).

\section{Mode of presentation}

Figure 1 illustrates the mode of initial presentation of our patients. Forty-four patients had clinically important presentation at diagnosis. Syncope without convulsion was the most common mode of presentation (37.3\%), among which around 40\% of cases were stress-related. Convulsion was also a common symptom (12\%). Aborted cardiac arrest occurred in six (10.2\%) individuals.

Three patients presented with sinus bradycardia, one of whom was detected prenatally. Four patients, including three infants, had 2:1 atrioventricular (AV) block at diagnosis. A significant proportion of patients with LQTS (25.4\%) did not have clinically important presentation at diagnosis; most of them had incidental ECG findings of prolonged QTc during medical check-ups or were identified by family cascade screening.

\section{Treatment and outcome}

The clinical outcomes of patients with LQTS in our cohort with clinically important presentation are summarised in Figure 2.

\section{Beta blocker}

All patients were offered beta blocker therapy. However, 14 patients refused beta blocker (11 patients had clinically important presentation). Seven patients were on beta blocker but stopped subsequently.

Metoprolol was the initial choice of beta blocker for most of our patients $(n=27)$, whereas 10 patients had atenolol as initial choice. Propranolol was used in eight infants. Eight patients receiving metoprolol, atenolol, or propranolol later changed to nadolol to enhance compliance or for better control of breakthrough symptoms. Mexiletine was added as an adjuvant therapy for five patients with LQTS type 3 (LQT3) who were symptomatic. Among the 31 patients with an initial history of convulsion, syncope, or dizziness (mean follow-up duration, $4.81 \pm 3.84$ years), 21 became asymptomatic after medication and/or lifestyle modification. Two patients who had recurrent symptoms after initial beta blocker therapy became event-free after a change from metoprolol/atenolol to nadolol. Patients without clinically important presentation at

TABLE I. Cohort characteristics of patients with LQTS

\begin{tabular}{|c|c|c|c|c|c|c|c|c|}
\hline & $\begin{array}{l}\text { Entire cohort } \\
\qquad(n=59)\end{array}$ & $\begin{array}{l}\text { Presentation } \\
\text { positive* } \\
(n=44)\end{array}$ & $\begin{array}{l}\text { Presentation } \\
\text { negative* } \\
(n=15)\end{array}$ & $P$ value & $\begin{array}{l}\text { LQTS type } 1 \\
\qquad(n=10)\end{array}$ & $\begin{array}{l}\text { LQTS type } 2 \\
\quad(n=12)\end{array}$ & $\begin{array}{l}\text { LQTS type } 3 \\
\qquad(n=7)\end{array}$ & $P$ value \\
\hline Male, No. (\%) & $33(55.9 \%)$ & $25(56.8 \%)$ & $8(53.3 \%)$ & NS & $9(90.0 \%)$ & $8(66.7 \%)$ & $3(42.9 \%)$ & NS \\
\hline $\begin{array}{l}\text { Age at diagnosis, mean } \pm S D \\
\text { (years) }\end{array}$ & $8.12 \pm 5.19$ & $8.75 \pm 5.12$ & $9.27 \pm 7.43$ & NS & $7.15 \pm 3.30$ & $8.84 \pm 6.25$ & $7.50 \pm 6.41$ & NS \\
\hline $\mathrm{QTc}$ at diagnosis, mean $\pm \mathrm{SD}(\mathrm{ms})$ & $504 \pm 47$ & $514 \pm 48$ & $476 \pm 27$ & 0.005 & $499 \pm 50$ & $518 \pm 39$ & $506 \pm 68$ & NS \\
\hline Schwartz score, median (range) & $4(1-6)$ & $4(3-6)$ & $3(1-4)$ & $<0.001$ & $5(3-5.5)$ & $5(3-6)$ & $4(1-5)$ & NS \\
\hline Proband, No. (\%) & $50(84.7 \%)$ & $43(97.7 \%)$ & $7(46.7 \%)$ & - & $9(90.0 \%)$ & $11(91.7 \%)$ & $5(71.4 \%)$ & NS \\
\hline
\end{tabular}

Abbreviations: LQTS = long QT syndrome; NS = not statistically significant; QTc = QT interval; SD = standard deviation

* 'Presentation' refers to clinically important presentation 

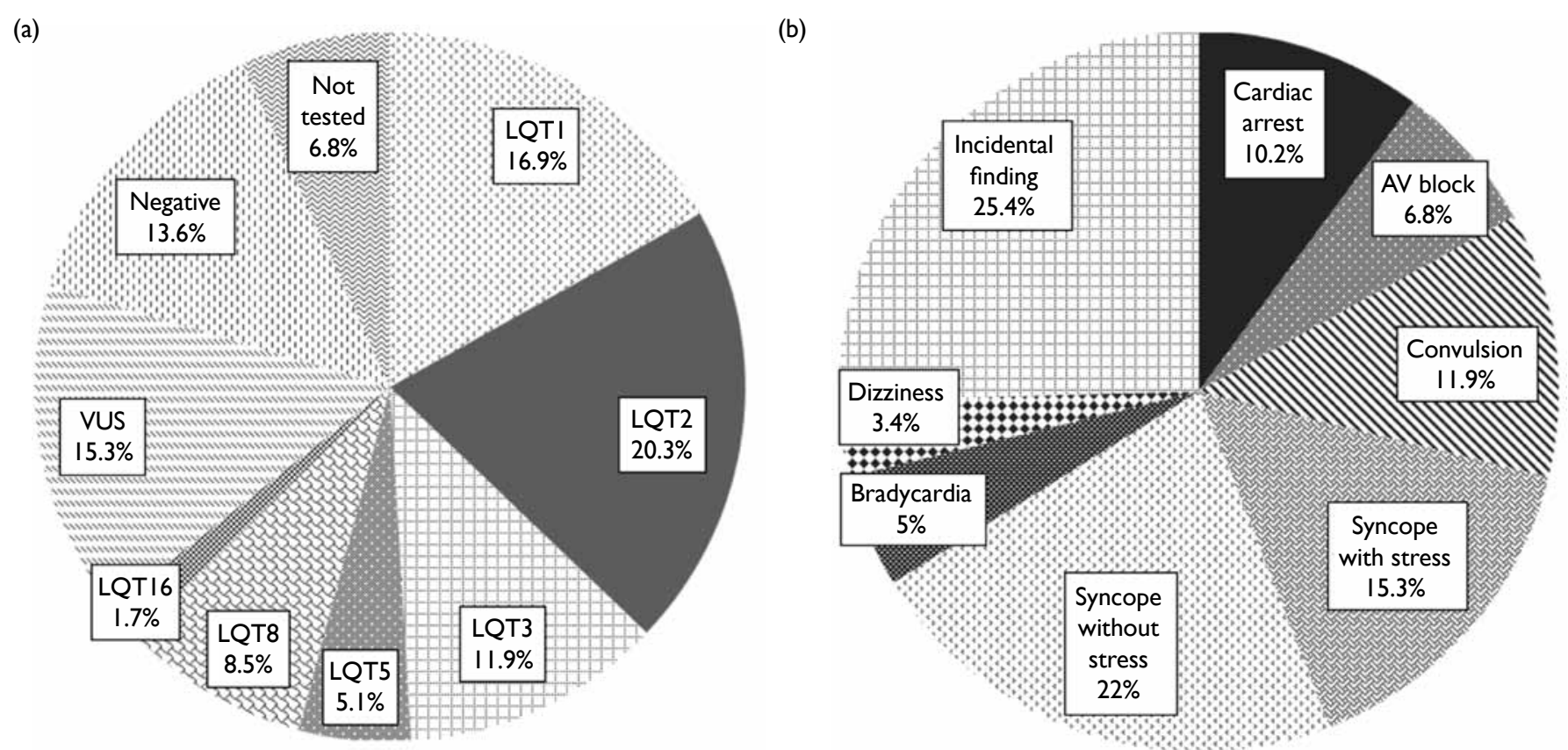

FIG I. Genotypes and clinical presentations of our cohort of patients with long QT syndrome ( $n=59)$. (a) Genotypes and (b) clinical presentations of patients with long QT syndrome

Abbreviations: AV block = atrioventricular block; LQT = long QT syndrome; VUS = variants of unknown significance

diagnosis remained asymptomatic with or without beta blocker therapy, irrespective of presence of documented pathogenic mutation.

\section{Implantable cardioverter defibrillator}

Implantable cardioverter defibrillator was implanted in 13 patients, whose mean QTc was $501 \pm 42 \mathrm{~ms}$. Six of these patients had initially presented with aborted ventricular tachycardia (VT)/ventricular fibrillation (VF) arrest. Five patients received ICD implantation because of recurrent symptom or subsequent VT/ VF despite beta blocker therapy. Two of these five patients experienced appropriate shocks after ICD implantation. One patient with pathogenic KCNE1 mutation had syncope due to sinus arrest with long pauses; ICD was offered for primary prevention of sudden death in addition to pacing therapy. One patient who had AV block at birth developed subsequent unprovoked syncope at aged 6 years despite medical treatment and his pacing system was upgraded to ICD. In total, four patients experienced appropriate ICD shocks despite beta blocker treatment. There were no more ICD shocks after reinforcement of medication compliance, adjustment of dosage, and in one patient switching of metoprolol to nadolol.

\section{Left cardiac sympathetic denervation}

Left cardiac sympathetic denervation was performed via video-assisted thoracoscopic approach in two patients, together with ICD therapy. Both of them were free of cardiac events on follow-up.

\section{Pacemaker}

Pacemakers were implanted in five patients. Four of these five patients had functional AV block due to prolonged QTc. Normal AV node conduction recovered with time in these four children. The fifth patient had complete heart block after surgical repair of congenital heart condition (transposition of great arteries with ventricular septal defect).

The Kaplan-Meier survival curve is shown in Figure 3. Overall, the breakthrough cardiac eventfree survival was $93.0 \% \pm 0.034 \%$ at 1 year, $80.7 \% \pm$ $0.065 \%$ at 5 years, and $72.6 \% \pm 0.080 \%$ at 10 years for the entire cohort. Patients who had clinically important presentation at baseline had a higher risk of developing breakthrough cardiac events $(\mathrm{P}=0.048)$ compared with those who did not. There was no mortality during the study period.

\section{Genotype}

All but four patients underwent genetic testing. Testing was not possible in two patients owing to loss to follow-up before genetic testing could be offered; these two patients were strong phenotypes of LQTS with Schwartz scores of 4 and 5 points, respectively. The other two patients were first-degree relatives of 


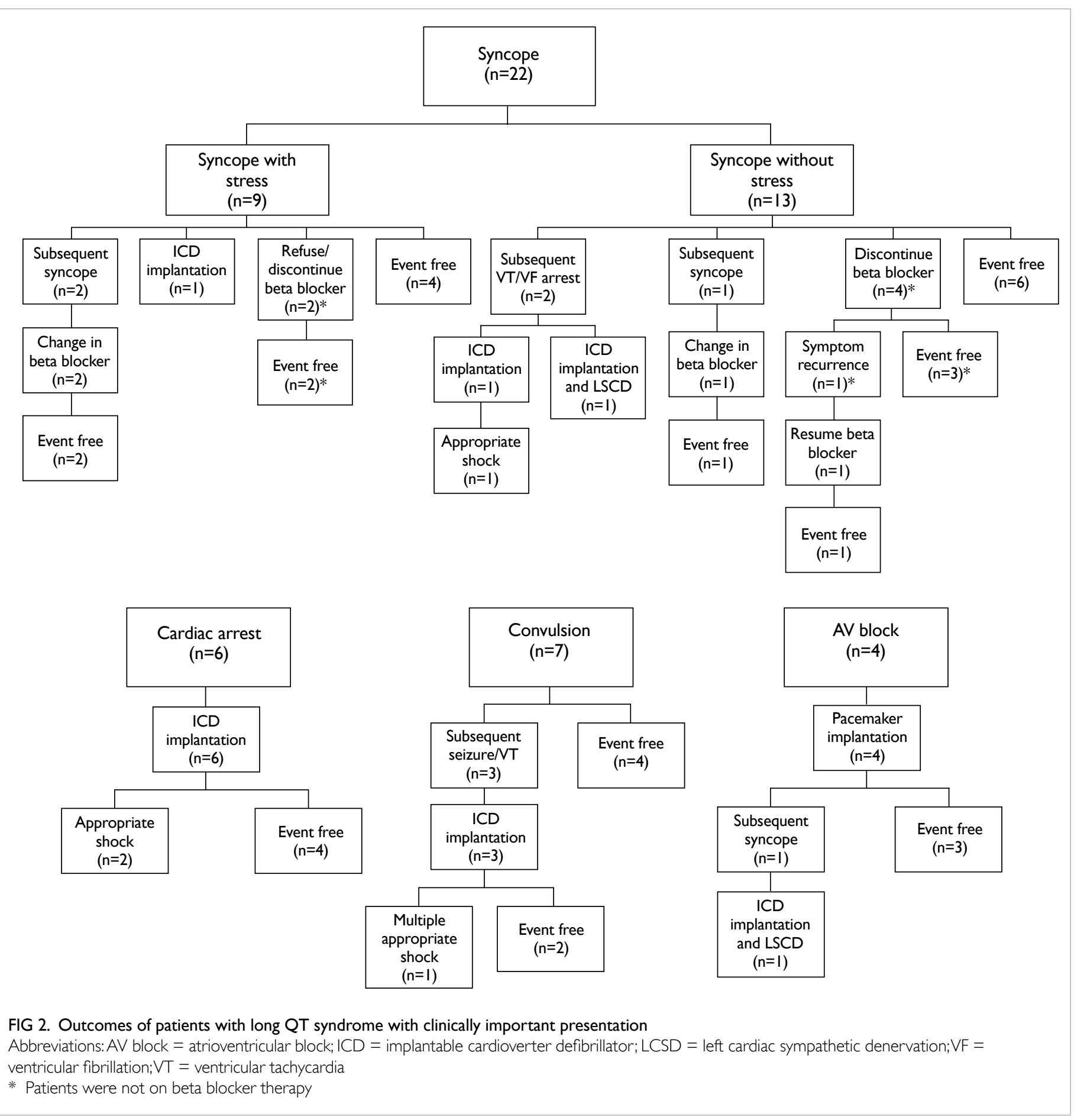

confirmed genotype-positive patients.

Seven patients were genotype negative. Four of them were tested before 2014. Nine patients had their mutated genes classified as variants of unknown significance. We also included three patients (LQT1, $\mathrm{n}=2$; LQT2, $\mathrm{n}=1$ ), reported by Mak et $\mathrm{al}^{7}{ }^{7}$ whose genetic tests were performed in a local laboratory.

Thirty-eight (69.1\%) patients among those tested were confirmed to have pathogenic mutations for LQTS (Table 2). Eight mutations were novel $(8 / 33,24.2 \%)$. Most of the pathogenic mutations were missense mutation (30/33, 90.9\%). Ten (16.9\%) patients had LQT1 (KCNQ1). Twelve (20.3\%) patients had LQT2 (KCNH2), whereas seven (11.9\%) patients had LQT3 $(S C N 5 A)$. Three patients had LQTS type 5 (KCNE1). There were five patients (three families) with LQT8 resulting from a rare pathogenic mutation in CACNA1C. LQT8 is linked 


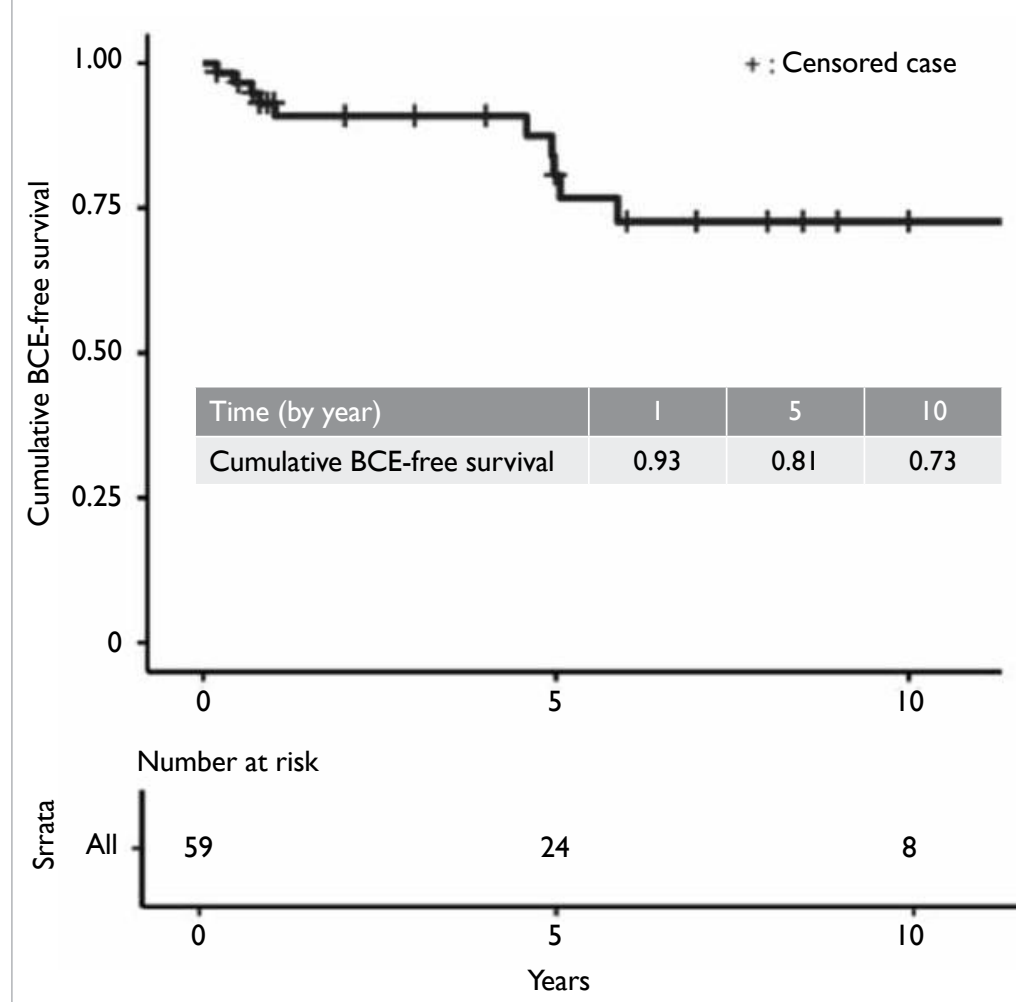

FIG 3. Breakthrough cardiac event (BCE)-free survival in treated long QT syndrome patients

\section{Discussion}

Long QT syndrome is a rare inherited disorder associated with an increased propensity to polymorphic VT/VF, syncope, and sudden cardiac death. In this report, we describe the clinical features and genetic profile of 59 LQTS paediatric patients managed in the only tertiary paediatric cardiology referral centre in Hong Kong over 20 years.

\section{Long QT syndrome diagnosis}

The prevalence of childhood LQTS was estimated to be 1:2000 in an Italian birth cohort. ${ }^{8}$ In a recent Japanese study, the estimated probability of diagnosing LQTS was 1:3300 in children aged 6 years and 1:1000 in those aged 12 years. ${ }^{9}$ Our results indicate that the prevalence of diagnosed LQTS in Hong Kong children was less than 1:10000, suggesting an underdiagnosis of the condition. This is likely due to under-recognition of symptomatic LQTS in young patients who were treated for recurrent seizure and unexplained syncope. Without an ECG screening programme, many asymptomatic LQTS children also remain undiagnosed.

The lack of comprehensive screening for family members of adult LQTS probands is another reason for underdiagnosis, as only two children from a single family were referred to us from adult cardiologists over the 20-year study period. In addition, a 5-yearold child of a mother with known LQTS was not referred until he presented with convulsions.

Molecular autopsy for young victims of sudden cardiac death is not implemented in Hong Kong. In many developed countries, affected family members of LQTS sudden death victims are identified early through this pathway to prevent sudden cardiac death. We believe that the total number of symptomatic and asymptomatic young patients with LQTS in Hong Kong is much higher than what we have studied in our single tertiary referral centre. ${ }^{10,11}$

\section{Long QT syndrome presentation}

Congenital LQTS is usually diagnosed in patients presenting with syncope, unexplained seizure, and aborted cardiac arrest. The mean QTc of our patients was $504 \pm 47 \mathrm{~ms}$, and median Schwartz score of the entire cohort was 4 points (range, 1-6 points). This indicates that the patients that were referred to our centre were patients with more severe symptoms, resulting in a higher likelihood of a diagnosis of LQTS, based on clinical criteria.

Previous reports have shown that the risk of clinical events in boys (aged $<15$ years) with LQTS is significantly higher than that in girls with LQTS. ${ }^{12}$ In our cohort, we also confirmed that symptomatic boys were significantly younger than girl at diagnosis or presentation. 
TABLE 2. Genetic information of our LQTS cohort (33 mutations in 38 patients)

\begin{tabular}{|c|c|c|c|c|c|}
\hline Nucleotide & Classification of mutation & Clinical implication & Coding effect & Protein position & Novel mutation \\
\hline \multicolumn{6}{|c|}{ Mutation in KCNQ1 (LQTS type 1) (NM_000218.2) } \\
\hline c. $532 \mathrm{G}>\mathrm{A}$ & Missense & Likely pathogenic & p.(Ala178Thr) & S2/S3 & \\
\hline c. $683 \mathrm{G}>\mathrm{T}$ & Missense/splicing & Likely pathogenic & p.(Arg228Met) & S4 & $\mathrm{Y}$ \\
\hline c. $782 A>G$ & Missense/splicing & Likely pathogenic & p.(Glu261Gly) & S4/S5 & $\mathrm{Y}$ \\
\hline c. $845 \mathrm{~T}>\mathrm{C}$ & Missense & Pathogenic & p.(Leu282Pro) & S5 & \\
\hline c. $965 \mathrm{C}>\mathrm{T}$ & Missense & Pathogenic & p.(Thr322Met) & Pore/S6 & \\
\hline c. $973 G>A$ & Missense & Pathogenic & p.(Gly325Arg) & Pore/S6 & \\
\hline c. $1018 \mathrm{~T}>\mathrm{C}$ & Missense & Pathogenic & p.(Phe340Leu) & S6 & \\
\hline c. $1032 \mathrm{G}>\mathrm{A}$ & Synonymous/splice & Pathogenic & p.(Ala344=) & S6 & \\
\hline c. $1831 \mathrm{G}>\mathrm{A}$ & Missense & Pathogenic & p.(Asp611Asn) & SAR & $\mathrm{Y}$ \\
\hline \multicolumn{6}{|c|}{ Mutation in KCNH2 (LQTS type 2) (NM_000238.3) } \\
\hline c. $211 \mathrm{G}>\mathrm{T}$ & Missense & Pathogenic & p.(Gly71Trp) & $\mathrm{N}$-terminus & \\
\hline c. $316 \mathrm{~T}>\mathrm{C}$ & Missense & Likely pathogenic & p.(Phe106Leu) & $\mathrm{N}$-terminus & $\mathrm{Y}$ \\
\hline c. $1501 \mathrm{G}>\mathrm{A}$ & Missense & Pathogenic & p.(Asp501Asn) & S3 & \\
\hline c. $1682 \mathrm{C}>\mathrm{T}$ & Missense & Pathogenic & p.(Ala561Val) & S5 & \\
\hline c. $1714 \mathrm{G}>\mathrm{A}$ & Missense & Pathogenic & p.(Gly572Ser) & S5/pore & \\
\hline c. $1750 \mathrm{G}>\mathrm{C}$ & Missense & Pathogenic & p.(Gly584Arg) & S5/pore & \\
\hline c. $1810 \mathrm{G}>\mathrm{A}$ & Missense & Pathogenic & p.(Gly604Ser) & S5/pore & \\
\hline c. $1810 \mathrm{G}>\mathrm{C}$ & Missense & Pathogenic & p.(Gly604Arg) & S5/pore & \\
\hline c.2233_2365del & Deletion/frameshift & Pathogenic & Unknown & CNBD & Y \\
\hline c. $3094 \mathrm{C}>\mathrm{T}$ & Missense & Likely pathogenic & p.(Arg1032Trp) & C-terminus & \\
\hline c.3102_3103dupCC & Duplication/frameshift & Pathogenic & p.(Arg1035Profs $\left.{ }^{\star} 23\right)$ & C-terminus & \\
\hline \multicolumn{6}{|c|}{ Mutation on SCN5A (LQTS type 3) (NM_001099404.1) } \\
\hline c. $1201 \mathrm{~T}>\mathrm{C}$ & Missense & Likely pathogenic & p.(Ser401Pro) & DI-S6 & Y \\
\hline c. $1231 \mathrm{G}>\mathrm{A}$ & Missense & Pathogenic & p.(Val411Met) & DI/DII & \\
\hline c. $3575 G>A$ & Missense & Pathogenic & p.(Arg1192Gln) & DII/DIII & \\
\hline c. $5287 \mathrm{G}>\mathrm{A}$ & Missense & Pathogenic & p.(Val1763lle) & DIV-S6 & \\
\hline c. $5296 A>C$ & Missense & Likely pathogenic & p.(Met1766Leu) & DIV-S6 & \\
\hline c. $5347 \mathrm{G}>\mathrm{A}$ & Missense & Pathogenic & p.(Glu1783Lys) & C-terminus & \\
\hline c. $5350 \mathrm{G}>\mathrm{A}$ & Missense & Pathogenic & p.(Glu1784Lys) & C-terminus & \\
\hline \multicolumn{6}{|c|}{ Mutation in KCNE1 (LQTS type 5) (NM_000219.5) } \\
\hline c. $242 A>G$ & Missense & Pathogenic & p.(Tyr81Cys) & C-terminus & \\
\hline c. $292 \mathrm{C}>\mathrm{T}$ & Missense & Pathogenic & p.(Arg98Trp) & C-terminus & \\
\hline \multicolumn{6}{|c|}{ Mutation in CACNA1C (LQTS type 8) (NM_199460.3) } \\
\hline c. $1186 G>C$ & Missense & Pathogenic & p.(Val396Leu) & DI-S6 & Y \\
\hline c. $1216 \mathrm{G}>\mathrm{A}$ & Missense & Pathogenic & p.(Gly406Arg) & DI/DII & $\mathrm{Y}$ \\
\hline c. $2573 G>A$ & Missense & Pathogenic & p.(Arg858His) & DII/DIII & \\
\hline \multicolumn{6}{|c|}{ Mutation in CALM3 (LQTS type 16) (NM_005184.3) } \\
\hline c. $286 \mathrm{G}>\mathrm{C}$ & Missense & Likely pathogenic & p.(Asp96His) & EF-hand 3 & \\
\hline
\end{tabular}

Abbreviation: LQTS = long QT syndrome

Sinus bradycardia and functional AV block are presentation. Their AV conduction normalised well reported in perinatal LQTS. ${ }^{13-15}$ The youngest with a significant decrease in QTc during followpatient in our group presented with fetal bradycardia. up. Paediatricians or family doctors should suspect We also noted 2:1 AV block in three infants at LQTS in young infants with slow heart rates. 


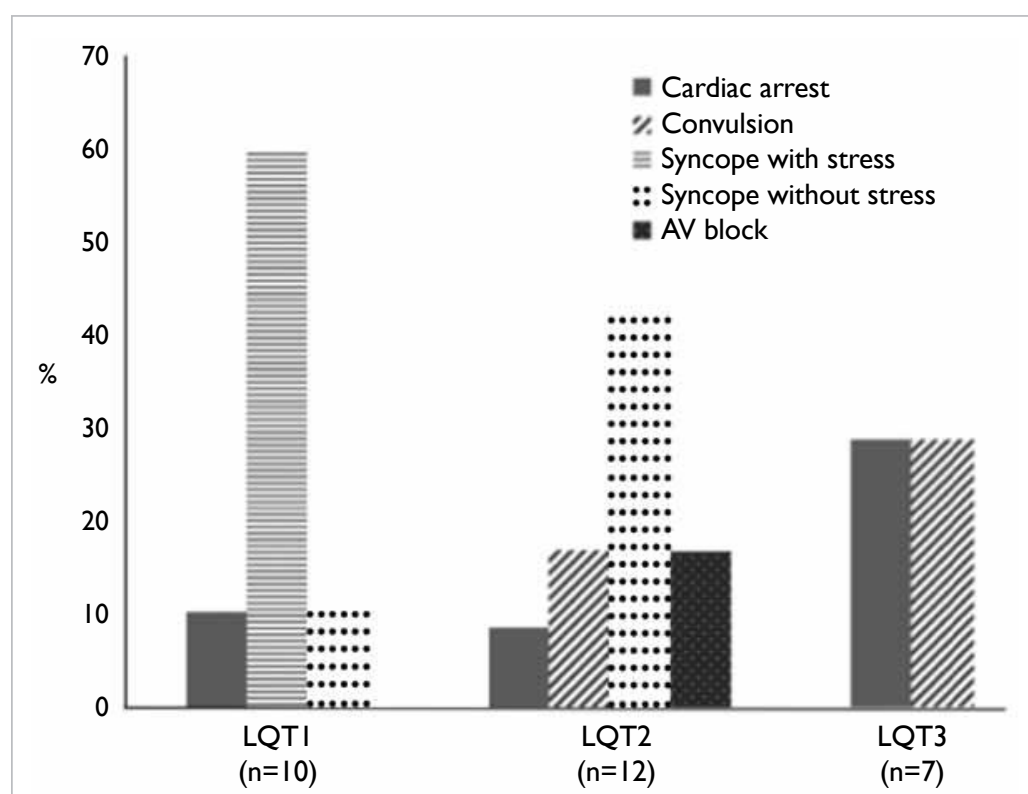

FIG 4. Clinically important presentation of patients with LQTI, LQT2, and LQT3 Abbreviations: $\mathrm{AV}$ block = atrioventricular block; $\mathrm{LQT}=$ long QT syndrome type

\section{Long QT syndrome and structural congenital heart disease}

Few links between LQTS and congenital heart disease have been reported, apart from Timothy syndrome. A recent single-centre review of 49 LQTS genotypepositive patients identified $11(22 \%)$ cases with concomitant conotruncal anomalies and/or aortic arch anomalies. ${ }^{16}$ In our cohort, five $(8.5 \%)$ patients with LQTS had concomitant congenital heart disease. Two cases were diagnosed in the perioperative period. Prolonged QTc in the context of congenital heart disease can be confounded by several factors, including postoperative electromechanical factors, intrinsic, or postoperative QRS abnormalities. Therefore, the diagnosis of LQTS could be masked in patients with congenital heart disease. We suggest that ECG of patients with congenital heart disease should be evaluated carefully for QTc.

\section{Long QT syndrome genotype}

Throughout the world, $75 \%$ to $80 \%$ of patients with LQTS have identifiable genetic mutations, with LQT1, LQT2, or LQT3 accounting for 90\% of cases. Pathogenic LQTS genetic mutations were identified in $69.1 \%$ of the patients in our cohort who were tested, which is comparable with other LQTS cohorts. ${ }^{17}$ Similarly, we had predominant genotypes of LQT1 (10/59, 16.9\%), LQT2 (12/59, 20.3\%), and LQT3 $(7 / 59,11.9 \%)$. In a recent single-centre study of LQTS in China, LQT2 was also the most common genotype. ${ }^{18}$ We also identified five $(8.5 \%)$ patients with rare CACNA1C (LQT8) mutations, all of whom were Hong Kong Chinese. Without a study of a large Chinese population in the past 5 years for cross reference, we cannot be certain whether LQT8 is more prevalent in Chinese than in other ethnic groups.

\section{Long QT syndrome management and outcome}

Beta blockers are the mainstay of treatment for all LQTS genotypes. In a registry of 1530 patients with LQTS, all beta blockers seemed equally effective in reducing risk of a first cardiac event after beta blocker initiation. For patients with LQT1, no single type of beta blocker has been found superior, although nadolol was found to be superior for patients with LQT2. ${ }^{19}$ However, another study suggested that symptomatic LQT1 and LQT2 patients on metoprolol had a higher rate of recurrence of cardiac events..$^{20}$ In the present study, 21 patients were prescribed metoprolol, two of whom required switching to another beta blocker due to recurrent symptoms. Because of the relatively short followup duration and small number of patients in our cohort, it is impossible to conclude on the efficacy of each beta blocker for patients with each genotype. Genotype-guided therapy is advocated in contemporary management in LQTS. Based on the available evidence, we are inclined to use nadolol as our first choice in symptomatic LQT2 patients. In symptomatic LQT3 patients, dual therapy using beta blockers and mexiletine are used. Mexiletine is a sodium channel blocker shown to shorten QTc in LQT3 patients. ${ }^{21,22}$

In addition to medical therapy with beta blockers, treatment of LQTS can also include lifestyle modifications, sympathetic denervation, and device therapy. With a multi-modality management strategy and genotype-guided therapy, outcome of LQTS have improved markedly over the past decades. The event-free survival was $96 \%$ at 1 year, $93 \%$ at 5 years, and $90 \%$ at 10 years, as reported recently in a large single-centre study which included $83 \%$ asymptomatic probands. ${ }^{23}$ In the present study, the breakthrough cardiac event-free survival was $93.0 \%$ at 1 year, $80.7 \%$ at 5 years, and $72.6 \%$ at 10 years (Fig $3)$. The event rate in the present study is likely higher than that of the abovementioned study because we have a higher proportion of probands (85\%), of whom $88 \%$ were symptomatic at presentation. Breakthrough cardiac events were mainly related to non-compliance to our treatment advice.

\section{Study limitations}

Our study was based on single-hospital data and referral bias is expected. We may have received referral of patients with LQTS with more severe symptoms. In addition, a short duration of followup in our patients (mean 5.3 years) may have led to underestimation of clinical cardiac events and mortality. 


\section{Future perspectives}

Our study demonstrated the high yield of genetic testing and the importance of genetic information in predicting the prognosis of patients with LQTS and guiding their treatment. Early identification of affected family members through cascade screening of mutated gene was also demonstrated. We hope that public genetic services can continue to develop, to enable genetic testing to be offered to all patients with suspected channelopathies. We also advocate the establishment in Hong Kong of inherited arrhythmia clinics or cardiac genetic clinics in the public sector, as implemented in many other countries. Such clinics have proven effectiveness in reducing sudden cardiac death associated with inherited arrhythmia syndrome. ${ }^{24}$

\section{Conclusion}

Our study provides insight into the clinical and molecular profiles of young patients with LQTS in the only tertiary paediatric cardiology referral centre in Hong Kong. The LQT1, LQT2 and LQT3 genotypes are the most common in mutation-positive patients. Early identification of LQTS, administration of beta blocker therapy, device therapy, and lifestyle modifications can prevent sudden cardiac death. However, the breakthrough cardiac event survival was only $72.6 \%$ at 10 years. Further optimisation of the treatment strategy by genotype-guided therapy may reduce recurrent symptoms and improve prognosis.

\section{Author contributions}

Concept and design: APY Liu, BHY Chung, TC Yung. Acquisition of data: SY Kwok, CYY Chan, TC Yung. Analysis or interpretation of data: SY Kwok, CYY Chan, JLF Fung, CCY Mak.

Drafting of the article: SY Kwok, APY Liu.

Critical revision for important intellectual content: BHY Chung, KS Lun, TC Yung.

\section{Acknowledgement}

We would like to express our gratitude to all paediatricians and physicians who referred patients with LQTS to our department, and to the adult cardiologists who cared for our grown-up patients. We are also grateful for the contributions of the local university laboratories and the pathology departments of Hospital Authority hospitals in conducting genetic tests on some of our patients. We would like to express our gratitude to Ms Yo-yo WY Chu for her participation in providing genetic services to our patients.

\section{Declaration}

All authors have disclosed no conflicts of interest. All authors had full access to the data, contributed to the study, approved the final version for publication, and take responsibility for its accuracy and integrity.

Results of this study were presented in the following meetings: (1) World Congress of Pediatric Cardiology \& Cardiac Surgery 2017, Barcelona, Spain, 16-21 Jul 2017; (2) The 13th Congress of Asian Society for Pediatric Research 2017, Hong Kong, 6-8 Oct 2017; (3) The 26th Annual Scientific Congress, Hong Kong College of Cardiology 2018, Hong Kong, 15-17 Jun 2018. Abstract of this study was published in the Journal of the Hong Kong College of Cardiology (Kwok SY, Liu AP, Lun KS, et al. Clinical and genetic profile of congenital long QT syndrome in Hong Kong-18-year experience in pediatrics. J HK Coll Cardiol 2018;26:60).

\section{Support/funding}

The expenses of the genetic analysis used in our study were sponsored by the Children's Heart Foundation of Hong Kong.

\section{Ethical approval}

This study received ethics approval from the Institutional Review Board of the University of Hong Kong/Hospital Authority Hong Kong Western Cluster.

\section{References}

1. Hobbs JB, Peterson DR, Moss AJ, et al. Risk of aborted cardiac arrest or sudden cardiac death during adolescence in the long-QT syndrome. JAMA 2006;296:1249-54.

2. Weintraub RG, Gow RM, Wilkinson JL. The congenital long QT syndromes in childhood. J Am Coll Cardiol 1990;16:674-80.

3. Mizusawa Y, Horie M, Wilde A. Genetic and clinical advances in congenital long qt syndrome. Circ J 2014;78:2827-33.

4. Giudicessi JR, Ackerman MJ. Calcium revisited: new insights into the molecular basis of long-QT syndrome. Circ Arrhythm Electrophysiol 2016;9:e002480.

5. Priori SG, Blomström-Lundqvist, Mazzanti A, et al. 2015 ESC Guidelines for the management of patients with ventricular arrhythmias and the prevention of sudden cardiac death: The Task Force for the Management of Patients with Ventricular Arrhythmias and the Prevention of Sudden Cardiac Death of the European Society of Cardiology (ESC). Endorsed by: Association for European Paediatric and Congenital Cardiology (AEPC). Eur Heart J 2015;36:2793-867.

6. Schwartz PJ, Crotti L. QTc behavior during exercise and genetic testing for the long-QT syndrome. Circulation 2011;124:2181-4.

7. Mak CM, Chen SP, Mok NS, et al. Genetic basis of channelopathies and cardiomyopathies in Hong Kong Chinese patients: a 10-year regional laboratory experience. Hong Kong Med J 2018;24:340-9.

8. Schwartz PJ, Stramba-Badiale M, Crotti L, et al. Prevalence of the congenital long-QT syndrome. Circulation 2009;120:1761-7.

9. Yoshinaga M, Kucho Y, Nishibatake M, Ogata H, Nomura Y. Probability of diagnosing long QT syndrome in children and adolescents according to the criteria of the HRS/ EHRA/APHRS expert consensus statement. Eur Heart J 2016;37:2490-7.

10. Kwok SY, Pflaumer A, Pantaleo SJ, Date E, Jadhav M, Davis AM. Ten-year experience in atenolol use and exercise evaluation in children with genetically proven long QT syndrome. J Arrhythmia 2017;33:624-9.

11. Marcondes L, Crawford J, Earle N, et al. Long QT molecular 
autopsy in sudden unexplained death in the young (1-40 years old): lessons learnt from an eight year experience in New Zealand. PLoS One 2018;13:e0196078.

12. Goldenberg I, Moss AJ. Long QT syndrome. J Am Coll Cardiol 2008;51:2291-300.

13. Cuneo BF, Strasburger JF, Yu S, et al. In utero diagnosis of long QT syndrome by magnetocardiography. Circulation 2013;128:2183-91.

14. Mitchell JL, Cuneo BF, Etheridge SP, Horigome H, Weng HY, Benson DW. Fetal heart rate predictors of long QT syndrome. Circulation 2012;126:2688-95.

15. Horigome H, Nagashima M, Sumitomo N, et al. Clinical characteristics and genetic background of congenital long-QT syndrome diagnosed in fetal, neonatal, and infantile life a nationwide questionnaire survey in Japan. Circ Arrhythmia Electrophysiol 2010;3:10-7.

16. Ebrahim MA, Williams MR, Shepard S, Perry JC. Genotype positive long QT syndrome in patients with coexisting congenital heart disease. Am J Cardiol 2017;120:256-61.

17. Schwartz PJ, Priori SG, Spazzolini C, et al. Genotypephenotype correlation in the long-QT syndrome: gene-specific triggers for life-threatening arrhythmias. Circulation 2001;103:89-95.
18. Gao Y, Liu W, Li C, et al. Common genotypes of long QT syndrome in China and the role of ECG prediction. Cardiology 2016;133:73-8.

19. Abu-Zeitone A, Peterson DR, Polonsky B, McNitt S, Moss AJ. Efficacy of different beta-blockers in the treatment of long QT syndrome. J Am Coll Cardiol 2014;64:1352-8.

20. Chockalingam P, Crotti L, Girardengo G, et al. Not all beta-blockers are equal in the management of long QT syndrome types 1 and 2 higher recurrence of events under metoprolol. J Am Coll Cardiol 2012;60:2092-9.

21. Wilde AA, Moss AJ, Kaufman ES, et al. Clinical aspects of type 3 long-QT syndrome: an international multicenter study. Circulation 2016;134:872-82.

22. Ruan Y, Liu N, Bloise R, Napolitano C, Priori SG. Gating properties of SCN5A mutations and the response to mexiletine in long-QT syndrome type 3 patients. Circulation 2007;116:1137-44.

23. Rohatgi RK, Sugrue A, Bos JM, et al. Contemporary outcomes in patients with long QT syndrome. J Am Coll Cardiol 2017;70:453-62.

24. Adler A, Sadek MM, Chan AY, et al. Patient outcomes from a specialized inherited arrhythmia clinic. Circ Arrhythm Electrophysiol 2016;9:e003440. 